\title{
Asylum seekers, refugees, and the politics of access to health care: a UK perspective
}

\author{
Keith Taylor
}

\author{
ABSTRACT \\ The UK government has recently consulted on \\ proposals to prohibit access to health care for some \\ asylum seekers. This discussion paper considers the \\ wider ethical, moral, and political issues that may arise \\ from this policy. In particular, it explores the \\ relationship between immigration and health and \\ examines the impact of forced migration on health \\ inequalities. It will be argued that it is both unethical \\ and iniquitous to use health policy as a means of \\ enforcing immigration policy. Instead, the founding \\ principle of the NHS of equal access on the basis of \\ need should be borne in mind when considering how \\ to meet the needs of this population. \\ Keywords \\ emigration and immigration; medical ethics; primary \\ health care; refugees.
}

'We must remember that the NHS is a national institution and not an international one ... The aim of these proposals is to ensure that the NHS is first and foremost for the benefit of residents of this country.' John Hutton (former Minister for Health, 2004) ${ }^{1}$

'It is the duty of a doctor ... to be dedicated to providing competent medical service in full professional and moral independence, with compassion and respect for human dignity.' World Medical Association, Geneva Declaration 1948²

\section{INTRODUCTION}

The UK government has recently consulted on proposals to exclude some 'overseas visitors', including asylum seekers, from NHS care. ${ }^{1} \mathrm{~A}$ judicial review took place at the high court in April 2008 regarding the rights of a failed asylum seeker to receive free hospital treatment in the $\mathrm{UK}^{3}{ }^{3}$ In this case the government's policy of selectively prohibiting access to care was initially overturned although the government was successful in its appeal against this verdict. ${ }^{4}$ This discussion paper will examine the wider ethical, moral, and political issues that are raised by this debate.

Studies suggest that in almost all indices of physical, mental, and social wellbeing, asylum seekers and refugees suffer a disproportionate burden of morbidity. ${ }^{5-8}$ This population is already disempowered and restricted in access to services, and any further policy moves to limit access may therefore be unjust and exacerbate existing inequalities.

Many of the tensions at the heart of this debate provoke wider questions regarding the ethics of population health. How should we fund our healthcare system? Who should be entitled to care? Where and when should rationing be applied? How does society conduct this debate? These are some of the defining questions in the health inequalities arena. This paper will argue that this debate also raises far-reaching questions about the relationship between the NHS, society, government, and international governance. 


\section{How this fits in}

Many individuals who seek asylum in the UK experience physical,

psychological, and social disadvantage and may be affected by barriers to care.

The Department of Health and the Home Office are currently reviewing the

conditions for access to NHS treatment by foreign nationals, including those

who are seeking refugee status. This paper highlights the potential tension that

arises between government policy and the duties of the individual health

professional. There is a need to separate clearly immigration and health policy.

\section{SOME DEFINITIONS}

The term 'refugee' covers immigrants at all stages in the asylum process. Under the Geneva Convention, this includes any individual fearing persecution for reasons of race, religion, nationality, social, or political group, and who is consequently unwilling or unable to return to their home country. ${ }^{9}$ The UK categorises refugees according to the definitions outlined in Box $1 . .^{10}$

The UK is a signatory to the European Convention on Human Rights, the United Nations Convention Against Torture, and the International Covenant on Economic, Social and Cultural Rights. These statutes oblige host countries to protect the most vulnerable people, offer 'the highest attainable standard of health', and specify not to limit equal access to health care. ${ }^{11}$

In some ways the Home Office application process is an attempt to homogenise an extremely diverse cohort. The demographic mix of the migrant population varies hugely, depending on the current geopolitical climate. ${ }^{12}$ Consequently, refugees' health needs are diverse and they may differ as much from each other as they do from the domestic population. Nevertheless, there are several unifying themes that affect all migrant groups in terms of their physical, psychological, and social wellbeing.

\section{THE UK ASYLUM PROCESS}

Ultimately, decisions on immigration lie with the UK Home Office. By definition, demographic data for this population are difficult to collect. Numbers are

\section{Box 1. Definitions of refugee status (adapted from Burnett and Peel, 2001). ${ }^{10}$}

- Asylum seeker: claim submitted (awaiting verdict).

- Refugee status: given leave to remain for 4 years and can then apply for indefinite leave. Restricted entitlement to family reunion.

- Indefinite leave to remain: indefinite residence. Restricted entitlement to family reunion.

- Exceptional leave to remain: right to remain for up to 4 years but expected to return to home country.

- Refusal: person has right of appeal within strict time limits and criteria. possibly underestimated, as only those living in the country who have lodged an official application or appeal are included. . $^{13,14}$

Pressure on migration is multifactorial and dependent on numerous host and recipient sociopolitical factors (including war, famine, and poverty). ${ }^{12}$ Recently, the most common nationalities seeking asylum have included Eritrean, Afghan, Iranian, Chinese, and Somali (countries where torture, war, anarchy, and other human rights abuses are commonplace). There is little evidence that migrants are specifically attracted by access to a higher standard of living or the welfare system..$^{11,15}$ Nevertheless, this remains a dominant perspective in some aspects of public debate. ${ }^{16}$

Asylum applications in the UK were at a peak of over 80000 in 2002. Since then, this has reduced and remained at approximately 25000 per year. The majority of applications tend to be unsuccessful. For example, of all applications lodged in 2006 only $10 \%$ were granted refugee status. Of those who were able to launch an appeal against this decision, $73 \%$ were dismissed. ${ }^{13}$

'Failed' asylum seekers are not necessarily 'bogus' asylum seekers, but have been unable to establish 'to a reasonable degree of likelihood' that they would suffer persecution if they were to return to their home nation. It is estimated that there may be as many as 450000 failed asylum seekers remaining in the UK..$^{17,18}$

For individuals the process can be lengthy, bureaucratic, and confusing. At any one time an individual may be lodging an application, awaiting a decision, awaiting an appeal, or have been refused asylum. For some this can take several years. ${ }^{19}$ The length and complexity of this process has been criticised by the United Nations (UN), the House of Commons Home Affairs Committee, and several campaign groups. $^{20}$ In comparison with its neighbours, the UK currently ranks 12th for number of asylum seekers per head of population. ${ }^{11}$

\section{HEALTH ISSUES AFFECTING ASYLUM SEEKERS}

Health needs assessment data for UK asylum seekers are scarce. ${ }^{21}$ Evidence suggests that asylum seekers fare worse than the UK population on almost all measures of health and wellbeing. The health effects of the immigration process may be considered in terms of the past and present consequences of forced migration (Figure 1).

For this group, there is an unequal distribution not only of ill-health but also of the social determinants of ill-health (including poverty, social isolation, literacy, self-efficacy, and so on). It is generally agreed that there is a reciprocal relationship between ill-health and these wider determinants. ${ }^{22}$ This is a 
crucial point in considering how to reduce health inequalities, as it may not simply be a question of providing 'more or better' health care. ${ }^{23}$

\section{Physical health}

Physical health needs of migrants tend to reflect the endemic spectrum of disease in their home country. Thus, infectious disease including HIV, tuberculosis, malaria, and other parasitic diseases are often more prevalent among immigrants from sub-Saharan Africa. $^{5,6}$ In many refugees from eastern Europe, higher rates of chronic disease, including diabetes and cardiovascular disease, have been reported. Other problems include poor dentition, malnutrition, and incomplete immunisation. In addition, health behaviour may be affected by forced migration. Several studies have reported a high prevalence of non-specific or somatising presentations as a result of psychosocial distress. ${ }^{8}$

\section{Psychological health}

It is unsurprising that symptoms of depression, anxiety, and agoraphobia have been reported among refugees and asylum seekers. ${ }^{5}$ These symptoms may result from stressors including bereavement, displacement, or torture. Many of these symptoms are further exacerbated by conditions in the host country, including compulsory detention, poverty, unemployment, housing, and social isolation. Different cultures have different models for conceptualising mental health and seeking help, which may complicate the provision of services such as counselling. ${ }^{24}$

Although high rates of post-traumatic stress disorder (PTSD) have been reported, ${ }^{25}$ much of the burden of illness may be beneath the level of formal psychiatric diagnosis. ${ }^{26}$ It is paradoxical, however, that those affected may only be able to seek help through a medical system that may stigmatise or label them. A diagnosis of PTSD may be sought in support of an asylum application. Some argue that the solutions to most psychological distress among refugees require social rather than medical intervention. ${ }^{8,24}$

\section{Financial issues}

Most asylum seekers and refugees are impoverished on arrival. Many may have specific skills and training that they are prevented from using in the UK, thus fostering a culture of dependence. ${ }^{27}$

Those who apply for asylum are subsequently entitled to benefits equivalent to approximately $70 \%$ of normal income support. This is dependent on remaining at a particular allocated accommodation. If an individual moves (which could be for reasons of seeking a social support network or because of racist abuse) or if their claim is refused, their benefits cease immediately, often leading to destitution.

Under the Immigration and Asylum Act 1999, most asylum seekers are not entitled to additional welfare benefits. As well as these theoretical restrictions, there are significant practical ones. For example, applicants on a low income can claim exemption from prescription charges if they complete an AG2 form. However, this is 16 pages long and available only in English. Therefore, there is a potential gap between entitlement to and provision of support. ${ }^{11}$

\section{Social issues}

Social isolation is common among migrants as they may be separated from their family, friends, and functional role in society. The effects of this can be powerful. One study of Iraqi refugees in the UK suggested that depression was more strongly associated with social isolation than with a past history of torture. ${ }^{28}$ Many immigrants are deprived of the principles of respect, autonomy, and selfefficacy, which are increasingly thought of as contributing to positive health. ${ }^{29}$

\section{Geographical issues}

Under the Immigration and Asylum Act 1999, many asylum seekers are relocated in areas with little experience of the needs of refugees. Some suggest that this may have worsened the problem of social isolation by actively discouraging integration. ${ }^{17,21}$ Accommodation for asylum seekers is often in areas of existing deprivation, and they therefore inherit the same social determinants of ill-health as the native population, yet with additional barriers to care.

Detention is a particularly controversial topic, as there is increasing evidence that it leads to adverse mental health outcomes. ${ }^{30,31}$ As well as prompting humanitarian concern, there is no evidence that this

Figure 1. Model of health effects of forced migration and refugee status.

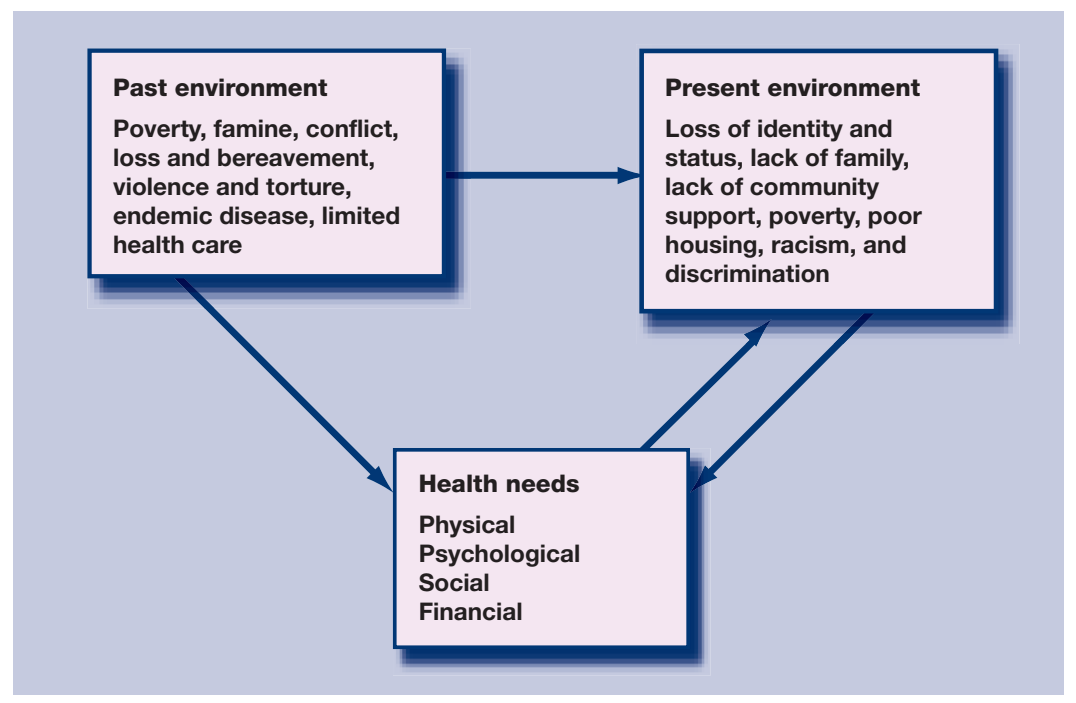


Table 1. Current entitlement of 'overseas visitors' to NHS treatment.

\begin{tabular}{|c|c|c|}
\hline Status & Primary care & Secondary care \\
\hline $\begin{array}{l}\text { - Asylum seeker } \\
\text { (application under consideration) } \\
\text { - Asylum seeker appealing refusal } \\
\text { - Asylum seeker denied financial } \\
\text { support but still claiming asylum } \\
\text { - Given refugee status } \\
\text { - Discretionary leave to remain } \\
\text { - Given humanitarian protection }\end{array}$ & \multicolumn{2}{|c|}{$\begin{array}{l}\text { Entitled to NHS treatment without charge (except prescription charges } \\
\text { where exempt). Can register with GP. Exempt from charges for NHS } \\
\text { hospital treatment }\end{array}$} \\
\hline $\begin{array}{l}\text { Failed asylum seekers (including those } \\
\text { awaiting departure) }^{\mathrm{b}}\end{array}$ & $\begin{array}{l}\text { - GP practices have discretion to } \\
\text { register under the NHS } \\
\text { - Emergency treatment free of charge }\end{array}$ & $\begin{array}{l}\text { - Not eligible for NHS treatment } \\
\text { - Life-saving treatment should not } \\
\text { be withheld but charge should be } \\
\text { pursued in the event of recovery } \\
\text { - If receiving treatment while under } \\
\text { appeal this should be continued } \\
\text { but discretion applied as to } \\
\text { when treatment is 'completed' } \\
\text { - Any further treatment is chargeable } \\
\text { - Some exemptions apply (for } \\
\text { example, tuberculosis) }\end{array}$ \\
\hline
\end{tabular}

a Humanitarian protection: technically this is not the same as asylum. The criteria for humanitarian protection are defined by the European Convention on Human Rights. The criteria for asylum are influenced by the United Nations Convention Relating to the Status of Refugees. 'The government's policy of selectively prohibiting access to care was initially overturned although the government was successful in its appeal against this verdict. ${ }^{4,39}$

functions as a 'deterrent' to immigration. This might suggest that this policy is being pursued more as a political gesture..$^{32}$

\section{Women and children}

The UN Convention on the Rights of the Child recognises that children often suffer disproportionately as a result of government policy. ${ }^{33}$ Children face a double burden of lack of provision of current basic needs and future loss of opportunity through lack of education, socialisation, and normal development. ${ }^{34,35}$

For women, there is the additional burden of child care and having to adapt to new roles and responsibilities. Women are more likely to report poor health and depression, yet in some cultures may be dependent on a man to disclose this. Women are often neglected in training and employment programmes. They are also more likely to suffer domestic violence and separation during periods of stress. ${ }^{36}$ Refugee women are also less likely to engage in screening, health promotion, family planning, and maternity services. ${ }^{7}$

There is a clear burden of need among this diverse population. At present the NHS barely meets these needs. Even if the government were to improve access and provision of services, many individuals would encounter other barriers that may be institutionally discriminatory. These include difficulties with literacy, cultural sensitivity, interpretation, confidentiality, and racism. ${ }^{37}$ For healthcare workers too, there is evidence of inadequate training, time, and resources to meet the needs of this group. ${ }^{38}$

\section{ACCESS TO CARE}

At present, government policy differentiates between access to primary and secondary care and between entitlement to 'routine' or 'emergency' treatment. The government also differentiates between failed asylum seekers and those who are applying for asylum. Current Department of Health guidance is summarised in Table $1 .{ }^{39}$

This two-tier system gives rise to several situations in which care may be deliberately withheld. For example, in the case of HIV, failed asylum seekers are entitled to testing and counselling but not to treatment of HIV with antiretroviral drugs. In the case of diabetes, patients may complete a course of treatment for complications but would not be entitled to ongoing care if their asylum appeal was subsequently unsuccessful.

Prior to the recent high court ruling, the government has advised that 'best practice is to ensure that overseas visitors are aware of the expectation to pay charges ... before they start treatment, so they can consider alternatives like a return home, if they are well enough to travel'.$^{40}$ Most undocumented and failed asylum seekers will, of course, be unable to pay and in effect will be refused treatment.

A further implication of this policy is that the onus is placed on healthcare staff to discern a patient's immigration status. Some argue that this places doctors in the impossible position of either breaking the law by maintaining the principles of 'Good Medical Practice' and providing care on the basis of 
need, or complying with the current political imperative by applying a discriminatory policy. .11,42 $^{40}$

Perhaps the fundamental issue here is the extent to which an individual doctor practising within the NHS is governed by a moral versus a political obligation. At present there is an uneasy tension between the NHS as a monopoly provider of health care on one hand, and on the other, the duty of the medical professional as an advocate for the care of the sick irrespective of issues of citizenship.

\section{The case of HIV}

The case of HIV exemplifies some of the implications of recent policy. People of 'uncertain immigration status' are currently entitled to treatment for sexually transmitted infection and illnesses that may be a threat to public health. However, despite meeting these criteria, HIV is explicitly excluded from this list. There are a number of practical, ethical, and moral problems with this position.

First, there is a clear clinical case that treatment early in the disease may prevent long-term death, disease, and disability. Harm can therefore either be avoided in the present or at some point in the future (when there is a 'life-threatening situation' as defined by the Department of Health). There is no clear ethical argument for withholding intervention in the present, while permitting action in the future. ${ }^{43}$

Second, the concept of 'duty of easy rescue' holds, whereby minimal cost to an individual (the tax payer) should not prevent significant benefit to another (that is, to provide life-saving treatment). ${ }^{44}$ In the context of the NHS as a whole, the cost of treating refused asylum seekers with antiretroviral therapy is minimal compared to the cost of not acting and treating the eventual consequences. ${ }^{45}$

Third, current 'loopholes' in the system lead to discrepancies that may be inconsistent and arbitrary. For example, HIV treatment may be available through genitourinary departments where residential status may be withheld, but not in obstetric departments where the full cost of care would payable. Treatment is allowed for 'life-threatening' or 'immediately necessary' situations and it could be argued this should include antiretroviral treatment for all women of childbearing age.

\section{THE ETHICS OF POPULATION HEALTH}

It may be argued that the inverse care law applies to refugees in the UK, whereby disproportionate needs are met by insufficient access, empowerment, and provision. ${ }^{46,47}$ The government proposes to restrict entitlement to care further. The ethical implications of this approach to provision of health care may be far reaching. In particular, it challenges us to define the basic rights that all patients may be entitled to as opposed to those rights that may be regarded as discretionary. In many ways this debate highlights the modern tension between a libertarian and egalitarian perspective of health care..$^{48}$

The NHS was founded on the principle of universal care with equal access to all on the basis of need, and no charge at the point of care. For a number of

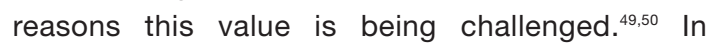
particular, there is uncertainty over what services should be funded by the NHS and whose rights should take precedence. ${ }^{51}$

Proponents of restricted access on the basis of citizenship argue that allowing treatment of those of uncertain or illegal status would lead to further pressure on migration and 'health tourism'. There is little evidence for this proposition. ${ }^{11}$ Most immigration is driven by much wider sociopolitical considerations than simply access to treatment. ${ }^{15,17,52}$

A further concern that has been raised is that the treasury should not fund highly expensive treatment to non-UK tax payers. There are three counterarguments to this. First in terms of cost-benefit analysis there is evidence that primary or secondary prevention (for example, antiretroviral therapy) may greatly curtail future spending on complications..$^{45}$ Second, the NHS does not currently differentiate between UK resident citizens on the basis of means. This is an extension of the libertarian view that all citizens have equal basic rights. ${ }^{53}$ Third, the government covertly prohibits asylum seekers from skilled employment, and hence integration and contribution to tax revenue.

It could be argued then that the government is confusing two difficult yet distinct decision-making processes: the decision on immigration status and the decision on access to treatment for those who are already resident in the UK. Furthermore, by linking asylum application to the provision of health care, the government may be forcing health professionals to collude in applying the sharp end of immigration policy. ${ }^{11}$

\section{TACKLING SOCIAL INJUSTICE}

If we accept then that current treatment of refugees in the UK is unjust, how should we move to reduce inequalities? As with many health inequalities, it is not simply a case of providing 'more or better' health care. Experience has shown that many inequalities persist over time ${ }^{54}$ We must then also attend to their root causes. In doing so we should be cautious about medicalising what may be largely social problems.

It is likely that many of the strategies for reducing health inequalities in this population may also empower other marginalised groups to achieve their potential. Such potential benefits ought to be 
considered in any broad economic analysis. A vast improvement in data collection and needs assessment is an obvious precursor to planning service provision..$^{5}$

\section{Practical solutions}

Health screening should be made routinely available on entry to the UK. Tuberculosis screening is already supposed to occur, although coverage is variable. ${ }^{6}$ The World Health Organization (WHO) strongly advises against compulsory testing for HIV due to fears it may be used to discriminate. Instead, immigrants should be offered voluntary testing and counselling.

One of the fundamental improvements in healthcare provision would be to overcome the information barrier. A coordinated interpretation and translation service may help interactions with healthcare staff. At present, this tends to vary significantly from area to area. The temptation to rely on family members should be avoided due to the potential for conflict of interest, although this should be challenged sensitively. ${ }^{56,57}$ Similarly, healthcare workers need prompt access to patients' records where available. Many asylum seekers tend to be registered as temporary residents, and a coordinated unified record may make this easier.

Many doctors mention time as a limiting factor in encounters with this group of patients. ${ }^{38}$ Some argue that unless care of this population is incentivised, it will succumb to the pressure of competing demands..$^{58}$ Others suggest that continuity of care and an open narrative approach may help to address complex presentations progressively. ${ }^{8}$ If so, then sophisticated communication skills may be required. ${ }^{56,57}$

Advocacy may be essential for vulnerable patients who are not sure of what they can and cannot expect from the health service. This may also offer a stepping stone between the health service and voluntary sectors. Some authors suggest that investment in advocacy workers may be more efficient than providing more healthcare staff. $^{58}$ Specific steps to improve the health of women and children may be undertaken by the extended role of the health visitor, and liaison with the voluntary sector and support networks where they exist.

There is a need for further training throughout the health sector in areas of cultural, religious, and gender sensitivity. ${ }^{19}$ Again, the benefits of this may apply to many other areas. Many of these strategies need multi-agency coordination, depending on the specific needs of the community.

\section{Social solutions}

There is convincing evidence that social integration improves health outcomes for refugees. ${ }^{30,31}$ Education, employment, and social networks are the three main routes. As well as reducing isolation and dependency, integration may also improve future opportunities and provide financial gain and a sense of self-worth. For children, successful integration into schools can be enormously therapeutic.

In many areas of deprivation there is a need to improve the basic minimum standard of housing available. ${ }^{59}$ Compulsory detention should be avoided on health and humanitarian grounds. ${ }^{31}$

Efforts to build social networks and support groups are necessary if a dispersal policy is to be successfully implemented. ${ }^{19}$ This would avoid the inevitable process of asylum seekers moving to bigger cities for support. Where possible, support groups should be led by asylum seekers themselves and encouraged to identify their own needs. A growing body of evidence demonstrates the positive health impact of promoting social inclusion. ${ }^{60}$

The role of the voluntary sector is critical. It is uniquely flexible and responsive to local needs. There is potential, however, for the unintended consequence of excusing mainstream NHS services from responsibility. In the provision of primary care, for example, this may lead to a fragmented and uncoordinated approach whereby 'core services' are increasingly provided outside the NHS. ${ }^{61}$

\section{Political solutions: advocacy and the medical profession}

The care of refugees may bring the medical profession into direct conflict with the government. ${ }^{62}$ The duty of a doctor as described by the General Medical Council is 'not to discriminate on the basis of race or background'. ${ }^{63}$ The Geneva Declaration of the World Medical Association specifically exhorts doctors not to allow '... considerations of age, disease or disability, creed, ethnic origin, gender, nationality, political affiliation, race, sexual orientation, social standing or any other factor to intervene between my duty and my patient'. ${ }^{2}$

Some have criticised the British Medical Association (BMA) for being ready to condemn human rights abuses in other countries while being reluctant to criticise the UK government's approach to domestic health rights; ${ }^{64}$ however, the BMA have responded to this criticism. ${ }^{65}$

One possible strategy for those who care for refugees is for doctors to offer voluntary or charitable care outside of the NHS. This may be difficult given the virtual monopoly that the NHS has on health care. The danger of this approach is that it may give rise to a piecemeal and unintegrated service that does not significantly reduce inequalities.

An alternative then is for the NHS as an employer to acknowledge that doctors may at times have a moral 
duty of care to patients that transcends their duty to the NHS itself. This is recognised to some extent in other contentious areas; for example, the right of doctors to object conscientiously to certain practices or, conversely, to exceed the norms of expected care.

Perhaps this argument is symptomatic of a greater contemporary tension within primary care between the utilitarian 'gatekeeper' and libertarian 'consumer-provider' roles. If primary care drifts further towards a consumerist model, then health inequalities may well widen. Moreover, there may be even less will or coordination among the profession to speak out and advocate against government policy.

\section{International perspective}

This debate is not confined to the UK, as similar moral and political arguments may confront all developed countries. The UK is a signatory to the International Covenant on Economic, Social and Cultural Rights, the International Covenant on Civil and Political Rights, and the Universal Declaration of Human Rights. Together these form the International Bill of Human Rights, ratified by the UK in 1976.

The fact that these agreements are not justiceable raises questions about the nature of international governance itself. Worldwide, there are at least 20 million refugees. Most of the burden for care of refugees is currently placed on neighbouring countries that are themselves often greatly under-resourced.

A further implication of international agreements is that while they necessitate shared responsibility, they also permit limited responsibility. Thus the UK need do no more than any other state. The counter-argument is that the UK is one of the wealthiest countries in the world, and as such may have a moral responsibility to care for its inhabitants accordingly, that is to say it should be 'leading rather than following'.

Others would claim that the UK presently targets significant debt relief overseas, and that this may be a more sustainable way of reducing forced migration at its source. In a sense this may be a false dichotomy, as the issue ought to be whether or not care is offered rather than where that care is delivered. The two options are not mutually exclusive, however. Developed countries could still attempt to tackle the root causes of forced migration while offering equal care to those individuals who are resident within their borders.

\section{CONCLUSION}

Ultimately, government policy is directed by political will, legislature, and public debate. This discussion raises questions of how this debate is conducted. Many support groups point to the relentlessly negative portrayal of refugees in the press. ${ }^{17,19}$ Political parties ought to resist the temptation to endorse these views for popular support alone. It could be argued that the medical profession is uniquely poised to advocate for the needs of patients, irrespective of issues of citizenship.

There is a wider debate taking placed in many liberal democracies about provision of universal health care. At present we may not possess the ethical framework and language to conduct this debate explicitly. ${ }^{51} \mathrm{~A}$ first step would be to separate healthcare policy from immigration policy. The government should then be more explicit about what healthcare services are available to all of its inhabitants.

An inevitable consequence of democratic decision making is that some people may differ and vote accordingly. Yet we should acknowledge that the decision-making process may be influenced by moral as well as political argument, and the medical profession has a responsibility to engage in this debate.

Loewy specifies three preconditions for a nation to achieve political democracy in a 'decent society'. ${ }^{66}$ First we should understand democracy as a moral value: this implies an individual respect for one another. Second, we should strive for economic democracy to minimise the gap between rich and poor. Third, educational democracy should offer the opportunity for all to achieve their potential. In the absence of these conditions, refugees might well ask themselves 'what is the state of democracy in the UK?'.

Migratory pressures are likely to increase significantly this century as a result of factors such as population growth, climate change, and political instability. On an international level we should attend to the route causes of migration. As individuals we may find ourselves considering who we wish to regard as a patient and who we do not. I would argue that as many refugees are already disadvantaged by the determinants and effects of migration, we should be cautious in implementing further barriers to care.

\section{Competing interests}

The author has stated that there are none.

\section{Discuss this article}

Contribute and read comments about this article on the Discussion Forum: http://www.rcgp.org.uk/bjgp-discuss

\section{REFERENCES}

1. Department of Health. Proposals to exclude overseas visitors from eligibility to free NHS primary medical services. A consultation. London: Department of Health, 2004.

http://www.dh.gov.uk/assetRoot/04/08/22/67/04082267.pdf (accessed 2 Jul 2009).

2. World Medical Association. World Medical Association International Code of Medical Ethics. Ferney-Voltaire, France: World Medical Association. http://www.wma.net/e/policy/c8.htm (accessed 2 Jul 2009).

3. Dyer O. News: Health department's denial of free health care to asylum seekers was unlawful, judge says. BMJ 2008; 336(7649): 849 .

4. Flory D. Failed asylum seekers and ordinary/lawful residence; and when to provide treatment for those who are chargeable. Dear colleague letter, Department of Health, 2 April 2009. 
http://www.dh.gov.uk/en/Publicationsandstatistics/Lettersandcirculars/ Dearcolleagueletters/DH_097384 (accessed 5 Aug 2009).

5. Walker PF, Jaranson J. Refugee and immigrant health care. Med Clin North Am 1999; 83(4): 1103-1120.

6. Dick B. Diseases of refugees - causes, effects and controls. Trans $R$ Soc Trop Med Hyg 1984; 78(6): 734-741.

7. Burnett A, Peel M. Health needs of asylum seekers and refugees. BMJ 2001; 322(7285): 544-547.

8. Burnett A, Peel M. Asylum seekers and refugees in Britain. The health of survivors of torture and organised violence. BMJ 2001; 322(7286): 606-609.

9. United Nations. Convention relating to the status of refugees. Geneva: United Nations, 1951

10. Burnett A, Peel M. Asylum seekers and refugees in Britain. What brings asylum seekers to the United Kingdom? BMJ 2001;322(7284) 485-488.

11. Hall P. Failed asylum seekers and health care. BMJ 2006; 333(7559): 109-110.

12. UNHCR: UN Refugee Agency. 2008 global trends: refugees, asylumseekers, returnees, internally displaced and stateless persons. UNHCR: UN Refugee Agency. http://www.unhcr.org/4a375c426.html (accessed 20 Aug 2009).

13. Bennett K, Heath T, Jeffries R. Asylum statistics United Kingdom 2006. Home Office Statistical Bulletin. 3rd edn. London: Home Office, 2007.

14. Bilsborrow RE, Hugo G, Oberai S, Zlotnik H. International migrations statistics: guidelines for improving data collection systems. Geneva: International Labour Office, 1997.

15. Glover S, Gott C, Loizillon A, et al. Migration: an economic and social analysis. RDS Occasional Paper No 67. London: The Home Office, 2001. http://www.homeoffice.gov.uk/rds/pdfs/occ67-migration.pdf (accessed 2 Jul 2009).

16. Raymond M. Tabloids blame asylum seekers for GP shortages. BMJ 2003; 326: 290

17. The Refugee Council. Basics on asylum http://www.refugeecouncil.org.uk/practice/basics/ (accessed 2 Ju 2009).

18. Stevenson R, Grant H. Land of no return. The Guardian, 13 June 2008 http://www.guardian.co.uk/uk/2008/jun/13/immigration.immigration policy (accessed 2 Jul 2009).

19. Barclay A, Bowes A, Ferguson I, et al. Asylum seekers in Scotland. Edinburgh, Scottish Executive Social Research, 2003

20. Amnesty International. Get it right: how Home Office decision making fails refugees. London: Amnesty International, 2004.

21. Audit Commission. Another country. Implementing dispersal under the Immigration and Asylum Act 1999. Abingdon: Audit Commission Publications, 2000

22. Evans RG, Barer ML, Marmor TR, editors. Why are some people health and others not? The determinants of health of populations. New York: Aldine de Gruyter, 1994

23. Evans RG, Stoddart, GL. Producing health, consuming health care. Soc Sci Med 1990; 31(12): 1347-1363.

24. Bracken P, Giller J, Summerfeld D. Psychological responses to war and atrocity: the limitations of current concepts. Soc Sci Med 1995; 40(8): 1073-1082.

25. Bison J. Post-traumatic stress disorder. BMJ 2007; 334: 789-793.

26. American Psychiatric Association. Diagnostic and statistical manual of mental disorders. 4th edn. Washington: American Psychiatric Association, 2000.

27. Pile $\mathrm{H}$. The asylum trap: the labour market experiences of refugees with professional qualifications. London: Low Pay Unit, 1997.

28. Gorst-Unsworth C, Goldenberg E. Psychological sequelae of torture and organized violence suffered by refugees from Iraq. Trauma related factors compared to social factors in exile. Br J Psychiatry 1998; 172: 90-94.

29. Sennett R. Respect: the formation of character in an age of inequality London: Penguin, 2004.

30. Porter M, Haslam N. Pre-displacement and post-displacement factor associated with mental health of refugees and internally displaced persons: a meta-analysis. JAMA 2005; 294(5): 602-612.

31. Arnold F. Detained asylum seekers may be being re-traumatised. $B M$ 2007; 334(7600): 916-917.

32. Fazel M, Silove D. Detention of refugees. BMJ 2006; 332(7536): 251-252.
33. UNICEF. Convention on the Rights of the Child. http://www.unicef.org/crc/ (accessed 2 Jul 2009).

34. Noglik A, Bassi Z. Eligibility of non-residents for NHS treatment: children of asylum seekers are special case. BMJ 2004; 329(7467): 683.

35. Fazel M, Stein A. UK immigration law disregards the best interests of children. Lancet 2004; 363(9423): 1749-1750.

36. Wallace T. Refugee women: their perspectives and our responses. Oxford: Oxfam, 1990.

37. Williams P. Why failed asylum seekers must not be denied access to the NHS. BMJ 2004; 329: 298 .

38. Ramsey R, Turner S. Refugees health needs. Br J Gen Pract 1993; 43(376): 480-481.

39. Department of Health. Asylum seekers and refugees: entitlement to NHS treatment. London: Department of Health, 2008.

http://www.dh.gov.uk/en/Healthcare/International/AsylumseekersAnd refugees/index.htm (accessed 2 Jul 2009).

40. Department of Health. Proposed amendments to the National Health Services (Charges to Overseas Visitors) Regulations 1989: a consultation. London: Department of Health, 2003.

41. Harding-Pink D. Humanitarian medicine: up the garden path and down the slippery slope. BMJ 2004; 329(7462): 398-399.

42. Forrest D, Barrett J. Ethical pitfalls can be hard to avoid. BMJ 2004; 329(7462): 399-400.

43. Rawls J. A theory of justice. Oxford: Oxford University Press, 1972.

44. Singer P. Practical ethics. Cambridge: Cambridge University Press, 1993.

45. Fowler A, Collins L, Larbalestier N, et al. HIV, HAART and overseas visitors. Sex Transm Infect 2006; 82(6): 516.

46. Watt G. The inverse care law today. Lancet 2002; 360(9328): 252-254.

47. Stirling AM, Wilson P, McConnachie A. Deprivation, psychological distress and consultation length in general practice. Br J Gen Pract 2001; 51(467): 456-460.

48. Berwick DM. A transatlantic review of the NHS at 60. BMJ 2008; 337: a838.

49. Klein R. What does the future hold for the NHS at 60 ? BMJ 2008; 337 a549.

50. Coombes R. NHS anniversary: the NHS debate. BMJ 2008; 337: 628

51. Roberts M, Reich M. Ethical analysis in public health. Lancet 2002; 359(9311): 1055-1059.

52. Romero-Ortuno R. Eligibility of non-residents for NHS treatment: failed asylum seekers should not be denied access to free NHS care. BMJ 2004; 329(7476): 683.

53. Kant I. The critique of practical reason. New York: Liberal Arts Press, 1956.

54. Acheson ED. Independent enquiry into inequalities in health. London: HMSO, 1998.

55. Scottish Needs Assessment Programme. A rough guide to needs assessment in primary care. Glasgow: Scottish Needs Assessment Programme, 1997.

56. Bischoff A, Perneger T, Bovier P, et al. Improving communication between physicians and patients who speak a foreign language. $\mathrm{Br} J$ Gen Pract 2003; 53(541): 546.

57. Phelan M, Parkman S. How to do it; work with an interpreter. BMJ 1995; 311(7004): 555-557.

58. Jones D, Gill P. Refugees and primary care: tackling the inequalities. BMJ 1998; 317(7170): 1444-1446.

59. British Medical Association. Housing and health: building for the future. London: British Medical Association, 2003.

60. Watt G. Policies to tackle social exclusion. BMJ 2001; 323(7306): 175-176.

61. Hull S, Boomla K. Primary care for refugees and asylum seekers. BMJ 2006; 332(7533): 62-63.

62. Forrest D, Barrett J. Ethical pitfalls can be hard to avoid. BMJ 2004; 329(7462): 399-400.

63. General Medical Council. Good medical practice. London: General Medical Council, 2004.

64. Hall P. Asylum seekers' health rights. BMA is in denial. BMJ 2007; 335(7621): 629.

65. Sheather J. BMA's response. BMJ 2007; 334: 917

66. Loewy E. The social nexus of healthcare. Am J Bioeth 2001; 1(2): 37. 